Case Report

\title{
A Case of Thermal Esophageal Injury Induced by Sodium Picosulfate with Magnesium Citrate
}

\author{
Dong-Hyuk Yang, Byoung Wook Bang, Kye Sook Kwon, \\ Hyung Kil Kim, and Yong Woon Shin
}

Division of Gastroenterology, Department of Internal Medicine, Inha University School of Medicine, Incheon, Republic of Korea

Correspondence should be addressed to Byoung Wook Bang; bangbu@inha.ac.kr

Received 2 April 2017; Accepted 14 May 2017; Published 4 June 2017

Academic Editor: R. J. L. F. Loffeld

Copyright (c) 2017 Dong-Hyuk Yang et al. This is an open access article distributed under the Creative Commons Attribution License, which permits unrestricted use, distribution, and reproduction in any medium, provided the original work is properly cited.

\begin{abstract}
Although thermal esophageal injuries caused by hot food or tea have been reported, thermal esophageal injury due to sodium picosulfate with magnesium citrate (PSMC) used for bowel preparation is rarely reported. We report the case of a 56-year-old man who presented with esophageal injury after ingestion of PSMC. Instead of dissolving the PSMC in water before ingestion, he drank water immediately after swallowing PSMC powder. As soon as he drank water, he developed severe chest pain and hematemesis. Upper endoscopy revealed severe hemorrhagic, ulcerative mucosal change from upper to mid-esophagus. He was hospitalized for nine days, received conservative treatment (fasting and parenteral nutrition), and recovered without complications. When PSMC is used as a colonic cleansing agent, patients should be educated to take it after dissolving it sufficiently in $150 \mathrm{~mL}$ of water to avoid esophageal thermal injury.
\end{abstract}

\section{Introduction}

Colonoscopic examination is increasing in Korea as a screen for colorectal cancer [1]. Bowel cleansing agents are very important for successful colonoscopy. Polyethylene glycol and PSMC are widely used bowel cleansers. Polyethylene glycol is the most commonly used laxative. However, it may cause adverse effects such as nausea, vomiting, and abdominal discomfort. In addition, it may be rejected due to its unpleasant odor and taste [2]. PSMC, which has a similar bowel cleansing effect, is used for easier administration. PSMC is a dual-action laxative that has an orange scent. The active components include sodium picosulfate, magnesium oxide, and citric acid. When PSMC is dissolved in water, magnesium oxide and citric acid combine to form magnesium citrate, which acts as osmotic laxative [2], and sodium picosulfate, a stimulant laxative [3]. Due to its dual action, PSMC is a powerful laxative and patients comply well because of the pleasant fragrance. However, inappropriate use of PSMC can cause serious side effects [2,3]. When it contacts water, an exothermic reaction occurs; therefore it should be dissolved in water and cooled before taking it. Here, we report a case of thermal injury of esophagus with acute bleeding caused by incorrect use of the PSMC.

\section{Case Report}

A 56-year-old man visited our hospital with severe chest pain and hematemesis. He was scheduled to receive colonoscopy in a local hospital. He did not sufficiently dissolve the PSMC powder in $150 \mathrm{~mL}$ of water as described in the drug instructions. Instead, he swallowed the PSMC powder and immediately drank water. Instantly after drinking water, he felt severe chest pain and shortly thereafter vomited about a cup of blood. On arrival at the emergency room, he was hemodynamically stable and alert. His blood pressure was $137 / 67 \mathrm{mmHg}$, pulse rate was 97 beats/minute, and body temperature was $36.8^{\circ} \mathrm{C}$. His initial hemoglobin level was $15.7 \mathrm{~g} / \mathrm{dL}$. Other results of laboratory tests were within normal ranges, including electrolyte level, coagulation test, and cardiac enzyme level. The chest radiograph showed no active lung lesions. We found no evidence of arrhythmic change or ischemic heart disease on the electrocardiogram. The patient underwent upper endoscopy (Figure 1) and we 


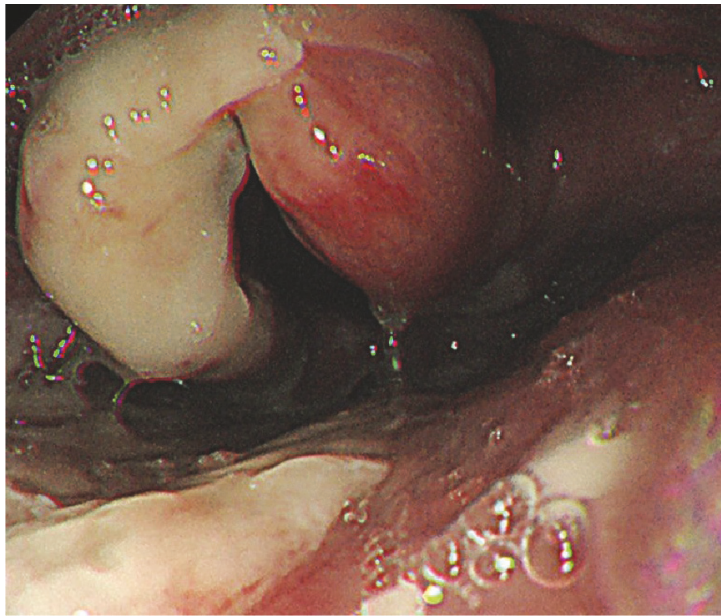

(a)

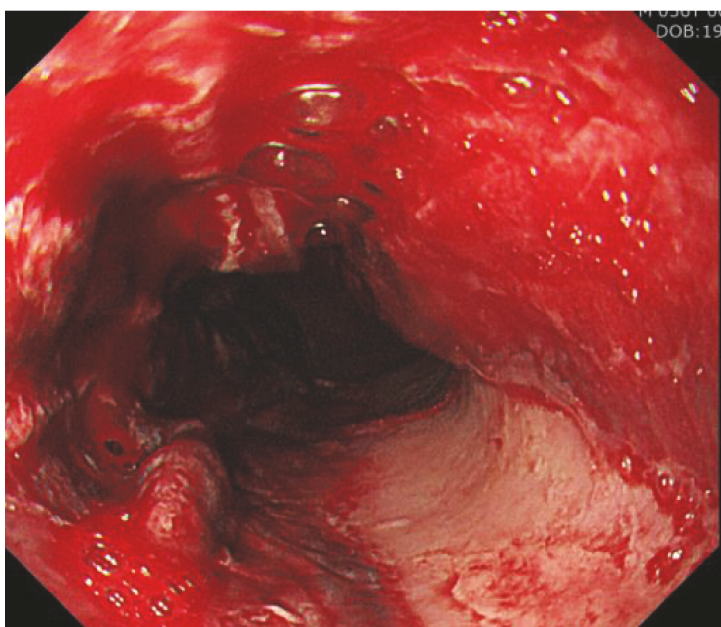

(c)

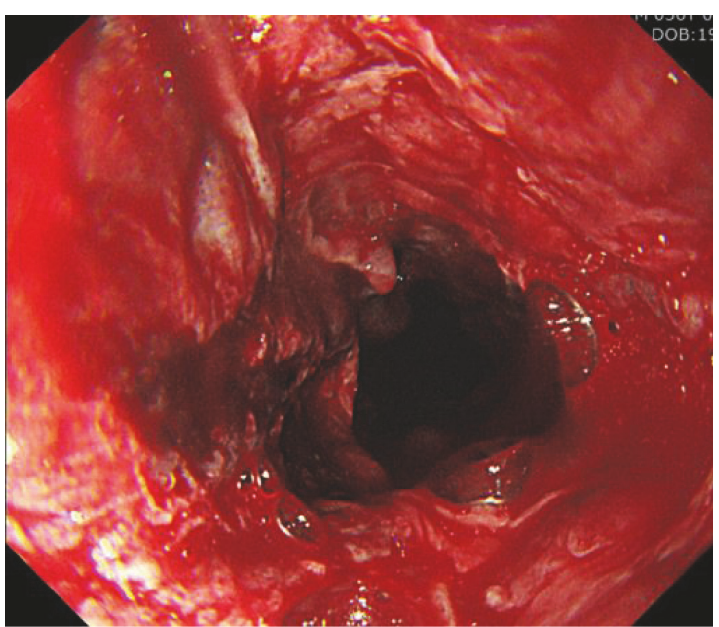

(b)

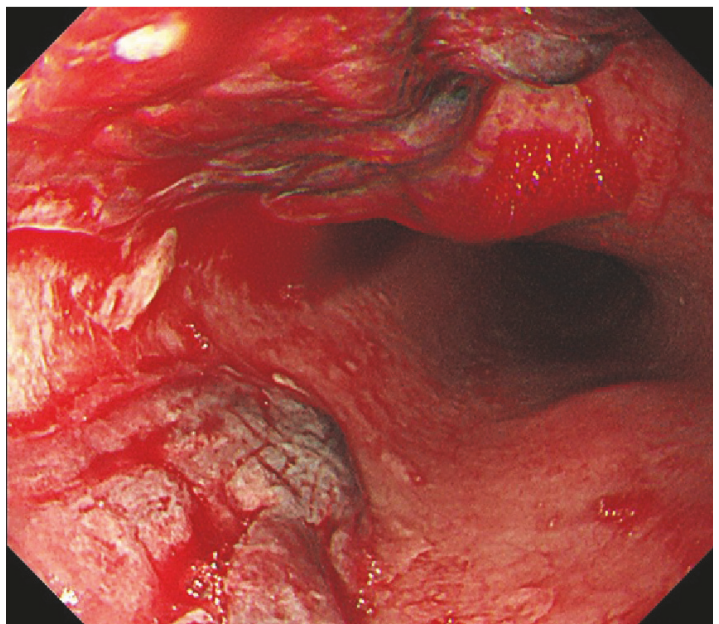

(d)

FIGURE 1: Upper endoscopy at admission. The epiglottis appeared swollen with moderate mucosal injury (a). Diffuse edematous and friable mucosa with deep ulceration and hemorrhage from the upper (b) to mid-esophagus ((c) and (d)).

detected diffuse edematous and friable mucosa with deep ulceration and oozing bleeding from the upper (Figure 1(b)) to mid-esophagus (Figures 1(c) and 1(d)). The epiglottis appeared swollen, although he did not complain of dyspnea (Figure 1(a)). Chest CT revealed diffuse mild esophageal wall thickening (Figure 2). Esophageal perforation or mediastinitis was not detected. The patient was diagnosed with acute thermal injury of esophagus by PSMC powder. During his hospital stay, he was treated conservatively, including fasting, empirical antibiotics, and parenteral nutritional support. Seven days after admission, endoscopy revealed that diffuse ulcerative lesions were improved with no more bleeding (Figures 3(a) and 3(b)). He started on a liquid diet and was discharged without any symptoms. Endoscopy one month later showed mild scarring without stricture (Figures 3(c) and $3(d))$, and he was free of symptoms.

\section{Discussion}

Acute thermal injuries of the esophagus can be caused by ingestion of hot solid or liquid materials [4-10]. The esophageal thermal injury caused by ingestion of hot liquid materials is characterized by a candy-cane appearance of alternating bands of whitish pseudomembrane and linear erythema [4-6]. On the other hand, esophageal injuries resulting from eating solid foods such as hot jelly roll [7], hamburger [8], and hot steamed eggs [9] appeared as a localized ulcer [7-9]. The reason for the different endoscopic findings from liquid and solid materials is that the candy-cane esophagus is caused by the transient rapid flow of hot liquids, whereas localized ulcers are caused by the pressure effect of hot solids. Therefore, the appearance of thermal injury of the esophagus varies depending on the type of ingested substance. In this case, not only localized deep ulcers but also linear erythema was observed in the esophagus. The reason for these atypical endoscopic findings was that the patient swallowed PSMC powder and drank water, resulting in slow movement of the semiliquid material from the pharynx to the upper esophagus.

PSMC is a low volume bowel cleansing agent that was introduced to the Korean market in 2011, although it has been 


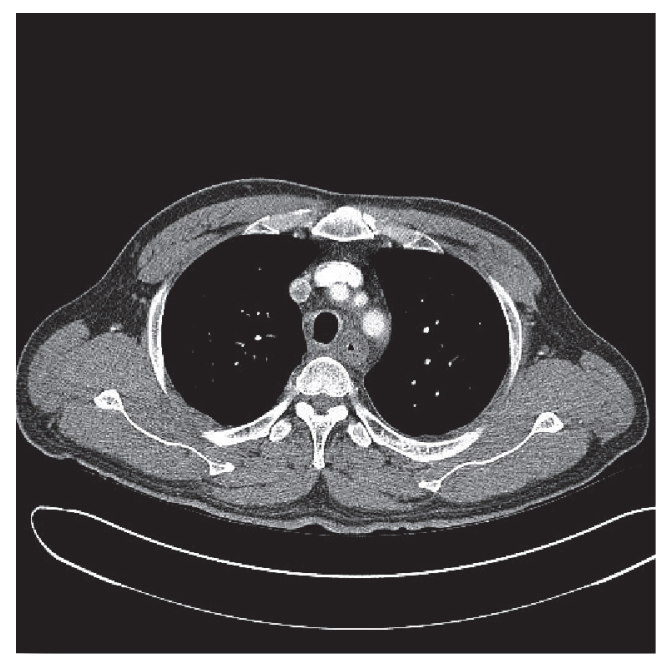

(a)

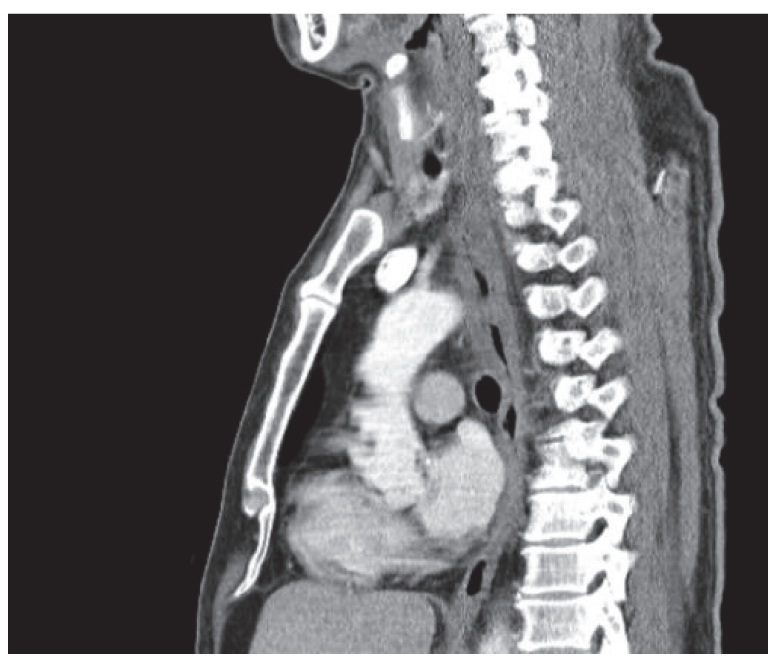

(b)

FIGURE 2: Chest computed tomography (CT). Transverse plain (a) and sagittal plain (b) images of the chest CT showed diffuse esophageal wall edema and thickening. However, esophageal perforation or mediastinitis was not detected.

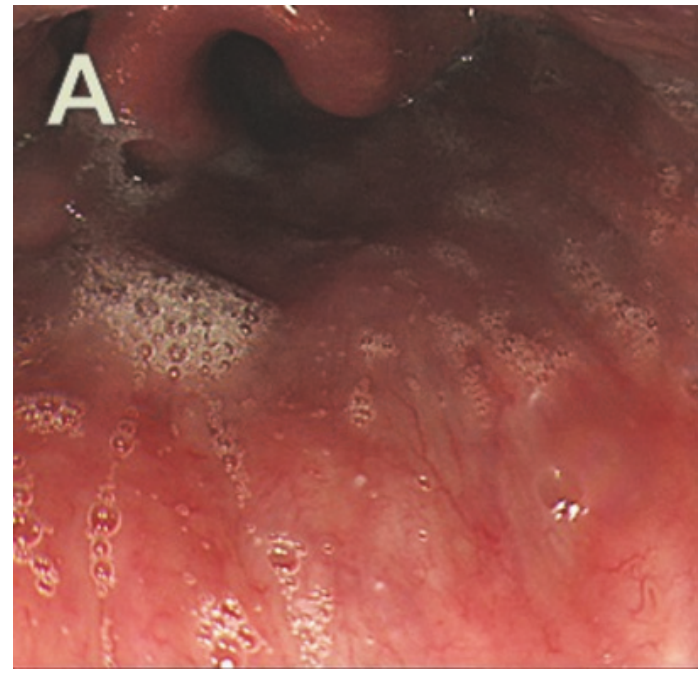

(a)

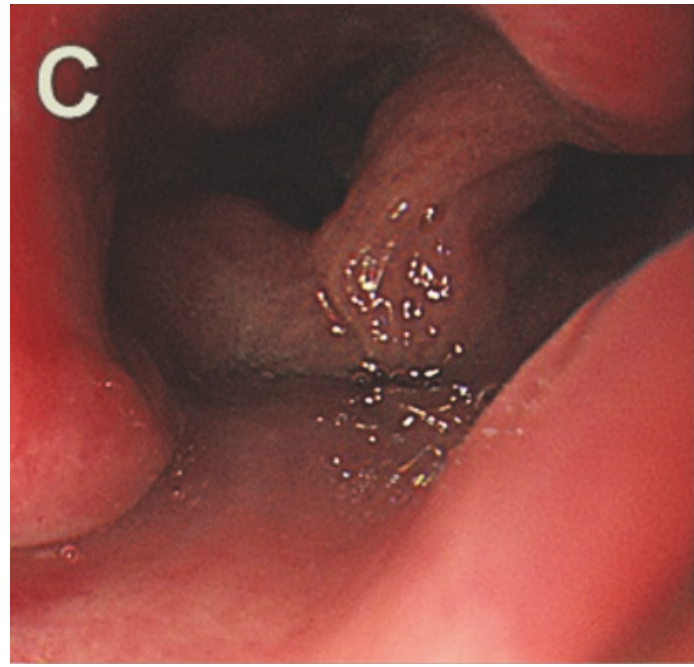

(c)

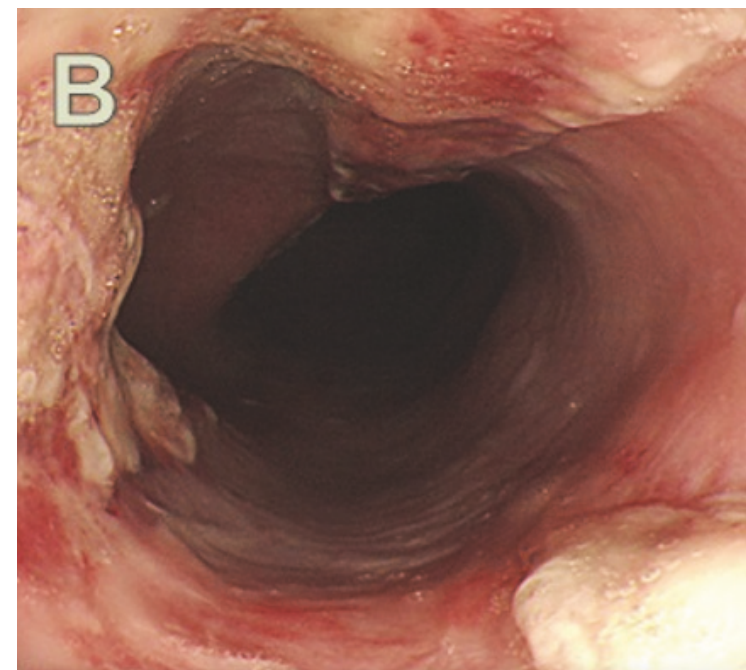

(b)

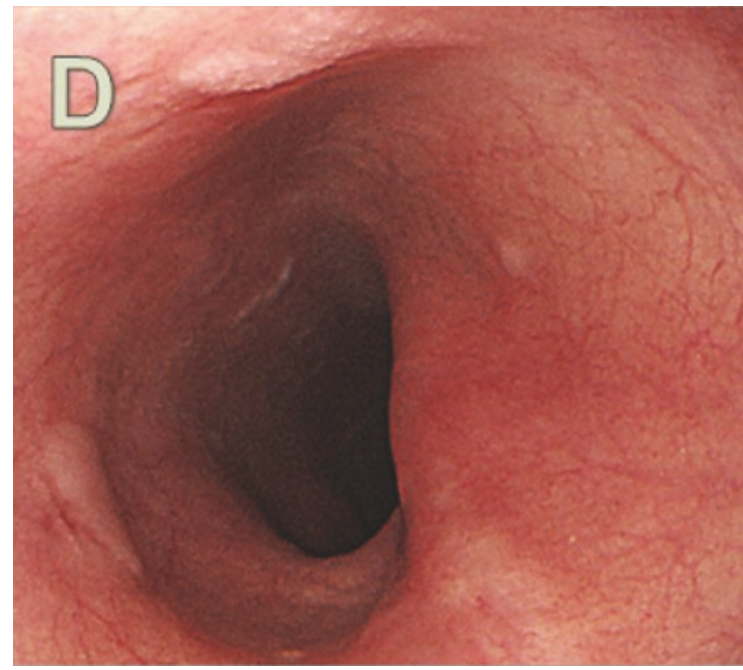

(d)

FIGURE 3: Upper endoscopy after conservative treatment. Endoscopic finding one week after thermal injury ((a) and (b)). The epiglottis was nearly healed and diffuse ulcerative lesions of the esophagus were improving without more bleeding. Endoscopic finding one month after thermal injury ((c) and (d)). The epiglottis was completely healed and whitish scars were seen in the esophagus. 


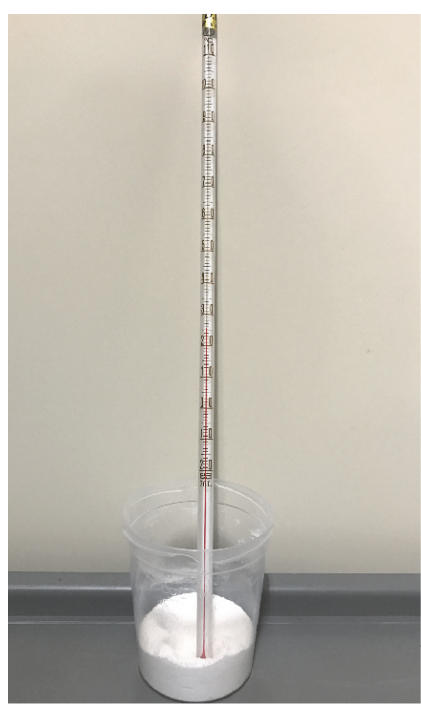

(a)

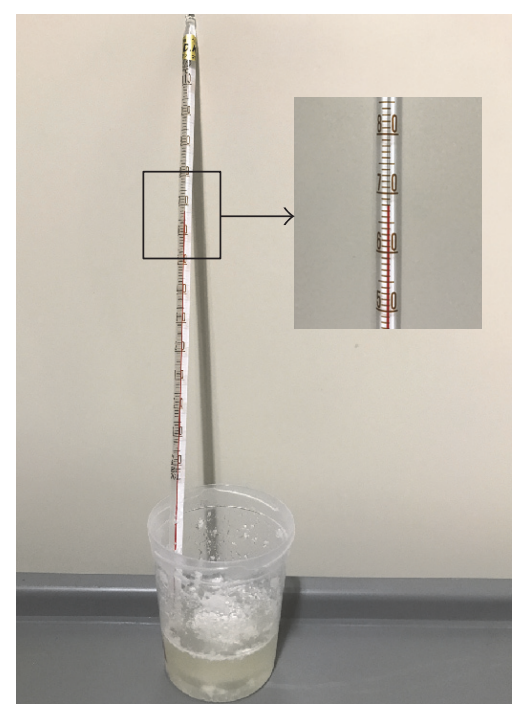

(b)

FIGURE 4: Exothermic reaction of Picolight ${ }^{\circledR}$ powder. (a) A pack of Picolight powder in a plastic container. The temperature of the powder was $25^{\circ} \mathrm{C}$. (b) The temperature was measured immediately after mixing the Picolight powder with $30 \mathrm{cc}$ of water. The temperature rose to $68^{\circ} \mathrm{C}$.

used widely for more than 20 years in European countries [11]. A pack of picosulfate with magnesium citrate (Picolight powder, Pharmbio, Seoul, Korea) consists of $10 \mathrm{mg}$ of sodium picosulfate, $3.5 \mathrm{~g}$ of magnesium oxide, and $12 \mathrm{~g}$ of anhydrous citric acid. An exothermic reaction occurs when magnesium oxide reacts with anhydrous citric acid to form magnesium citrate $\left(\mathrm{MgO}+\mathrm{C}_{6} \mathrm{H}_{8} \mathrm{O}_{7}+\mathrm{H}_{2} \mathrm{O} \rightarrow \mathrm{C}_{6} \mathrm{H}_{6} \mathrm{MgO}_{7}+2 \mathrm{H}_{2} \mathrm{O}\right)$. To confirm the exothermic reaction, the authors measured the temperature change after dissolving a pack of PSMC powder in water. When a pack of PSMC powder was poured into $30 \mathrm{~mL}$ of water and stirred, it boiled and the temperature rose to $68^{\circ} \mathrm{C}$ (Figure 4). Third-degree burn of skin can occur when hot water at $69^{\circ} \mathrm{C}$ contacts the skin for several seconds [12]. Thus, drinking water after swallowing PSMC powder will cause a severe thermal injury to the esophagus. In addition, when PSMC powder is dissolved in a small amount of water, it produces a strong acidic liquid, leading to corrosive esophagitis [13]. Therefore, although PSMC powder is considered safe, incorrect usage may lead to severe side events such as thermal injury of esophagus or stomach. It is recommended that PSMC should be completely dissolved in sufficient quantity of water and cooled before drinking. According to drug instructions, the PSMC powder should be dissolved in $150 \mathrm{~mL}$ of water before drinking.

To date, four cases of PSMC-related thermal injuries have been reported in Korea, including our case. The thermal injury occurred in the upper esophagus in our case, and in other cases it occurred in the esophagus and stomach $[11,14]$ and stomach $[15]$. Fortunately, all cases recovered with conservative management without complications such as esophageal stricture or perforation. However, considering the fact that PSMC is widely used as a colon cleansing agent and the fact that many cases of thermal injury may not have been reported, clinicians should educate the patients about exactly how to use this medicine to prevent these thermal injuries.
Treatment of esophageal thermal injury is conservative, including fasting, hydration, administration of proton pump inhibitor, and empirical antibiotics. The prognosis is generally favorable [4-10]. No esophageal stricture or perforation has been reported as a complication of esophageal thermal injury.

In conclusion, we report a case of esophageal thermal injury caused by the incorrect use of PSMC. Although acute thermal injury of esophagus has a favorable prognosis, appropriate management and careful observation are needed to prevent further damage. Endoscopists and dispensing pharmacists should educate patients to not swallow PSMC powder for bowel preparation.

\section{Conflicts of Interest}

The authors declare that there are no conflicts of interest.

\section{Acknowledgments}

This research was supported by the Inha University Research Grant.

\section{References}

[1] K. S. Choi, J. K. Jun, H.-Y. Lee, M.-I. Hahm, J. H. Oh, and E.C. Park, "Increasing uptake of colorectal cancer screening in Korea: a population-based study," BMC Public Health, vol. 10, article no. 265, 2010.

[2] J. Love, E.-J. Bernard, A. Cockeram et al., "A multicentre, observational study of sodium picosulfate and magnesium citrate as a precolonoscopy bowel preparation," Canadian Journal of Gastroenterology, vol. 23, no. 10, pp. 706-710, 2009.

[3] S. M. Hoy, L. J. Scott, and A. J. Wagstaff, "Sodium picosulfate/magnesium citrate: a review of its use as a colorectal cleanser," Drugs, vol. 69, no. 1, pp. 123-136, 2009. 
[4] S. K. Dutta, K. Y. Chung, and B. S. Bhagavan, "Thermal injury of the esophagus," New England Journal of Medicine, vol. 339, no. 7, pp. 480-481, 1998.

[5] M. E. Cohen and J. G. Kegel, "Candy cocaine esophagus," Chest, vol. 121, no. 5, pp. 1701-1703, 2002.

[6] E. K. Choi, H. L. Gin, H.-Y. Jung et al., "The healing course of thermal esophageal injury: a case report," Gastrointestinal Endoscopy, vol. 62, no. 1, pp. 158-160, 2005.

[7] D. A. Lieberman and E. B. Keeffe, "Esophageal burn and the microwave oven.," Annals of Internal Medicine, vol. 97, no. 1, p. 137, 1982.

[8] R. Eliakim, "Thermal injury from a hamburger: a rare cause of odynophagia," Gastrointestinal Endoscopy, vol. 50, no. 2, pp. 282-283, 1999.

[9] S. M. Kim, S. H. Jung, and Y. M. Kim, "Esophageal ulcer by thermal injury from steamed egg," Korean Journal of Gastrointestinal Endoscopy, vol. 32, no. 3, pp. 190-193, 2006.

[10] J. H. Lee, H. J. Kim, and T. H. Kim, "A case of epoxy resin induced thermal injury in upper gastrointestinal tract," Korean Journal of Gastrointestinal Endoscopy, vol. 30, no. 6, pp. 325-329, 2005.

[11] J. P. Suh, Y. S. Choi, and S. H. Lee, "Education and Imaging. Gastroenterology: acute mucosal injury of esophagus and stomach induced by sodium picosulfate/magnesium citrate for bowel preparation," Journal of Gastroenterology and Hepatology (Australia), vol. 29, no. 8, p. 1571, 2014.

[12] A. R. Moritz and F. C. Henriques, "Studies of thermal injury: II. The relative importance of time and surface temperature in the causation of cutaneous curns," The American Journal of Pathology, vol. 23, no. 5, pp. 695-720, 1947.

[13] K. Ramasamy and V. V. Gumaste, "Corrosive ingestion in adults," Journal of Clinical Gastroenterology, vol. 37, no. 2, pp. 119-124, 2003.

[14] J. Y. Seo, K. J. Kang, H. S. Kang et al., "Corrosive esophagitis caused by ingestion of picosulfate," Clinical Endoscopy, vol. 48, no. 1, pp. 66-69, 2015.

[15] D. S. Lee, H. S. Kim, S. H. Lee, J. H. Jeon, and Y. K. Lee, "A case of PICOLIGHT powder induced thermal injury of the gastric mucosa," The Korean Journal of Helicobacter and Upper Gastrointestinal Research, vol. 14, no. 1, pp. 58-60, 2014. 


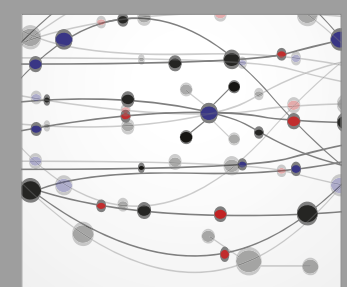

The Scientific World Journal
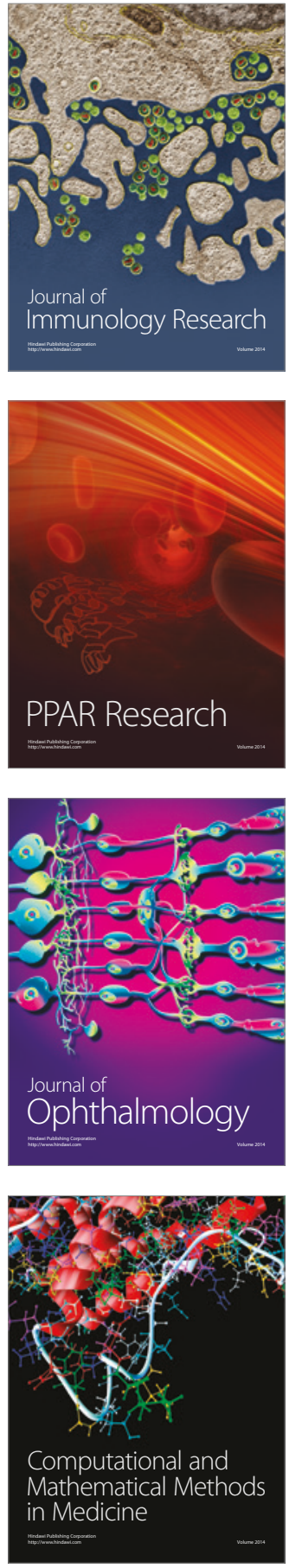

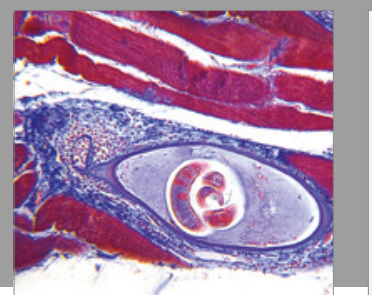

Gastroenterology Research and Practice
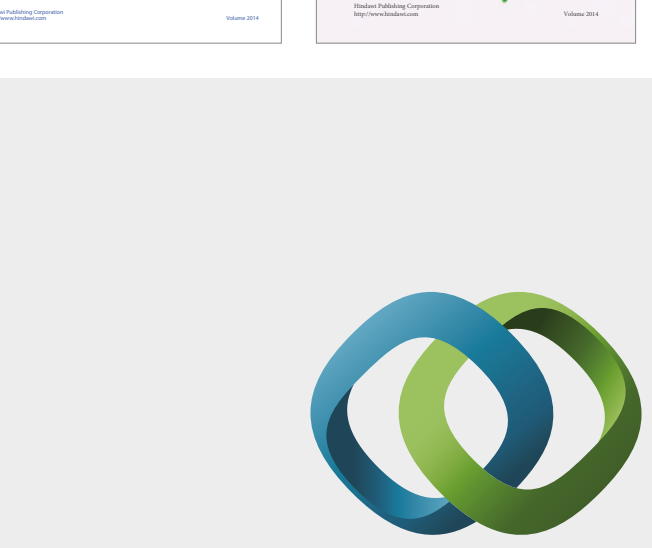

\section{Hindawi}

Submit your manuscripts at

https://www.hindawi.com
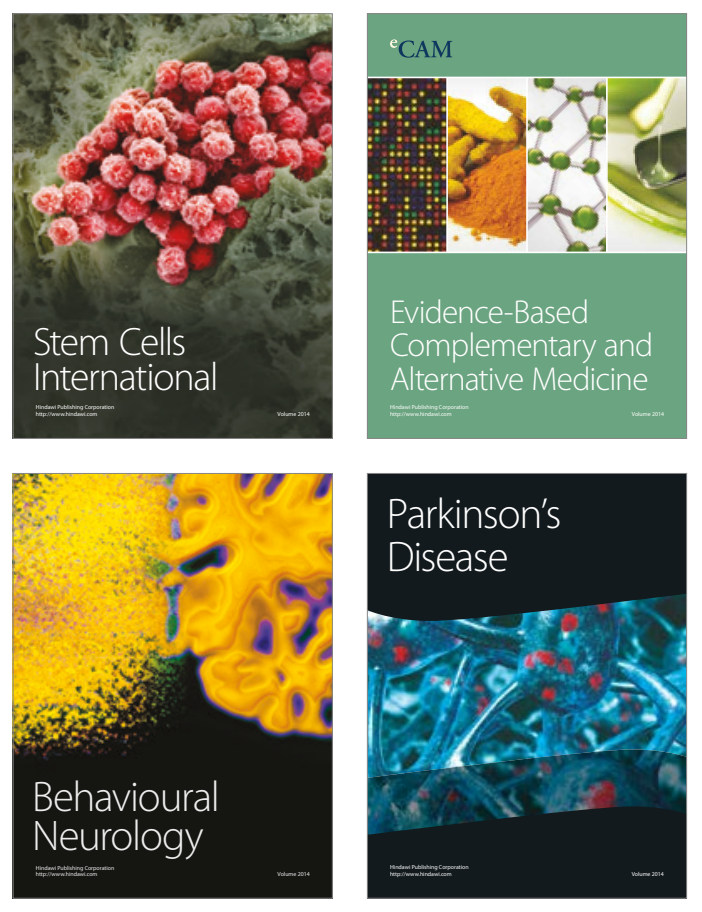
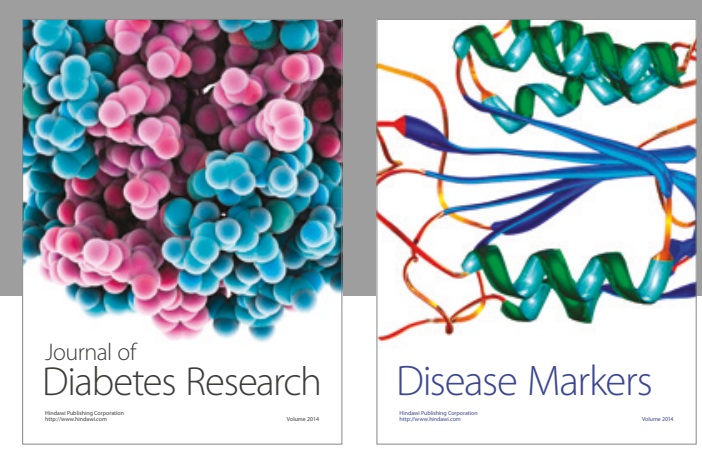

Disease Markers
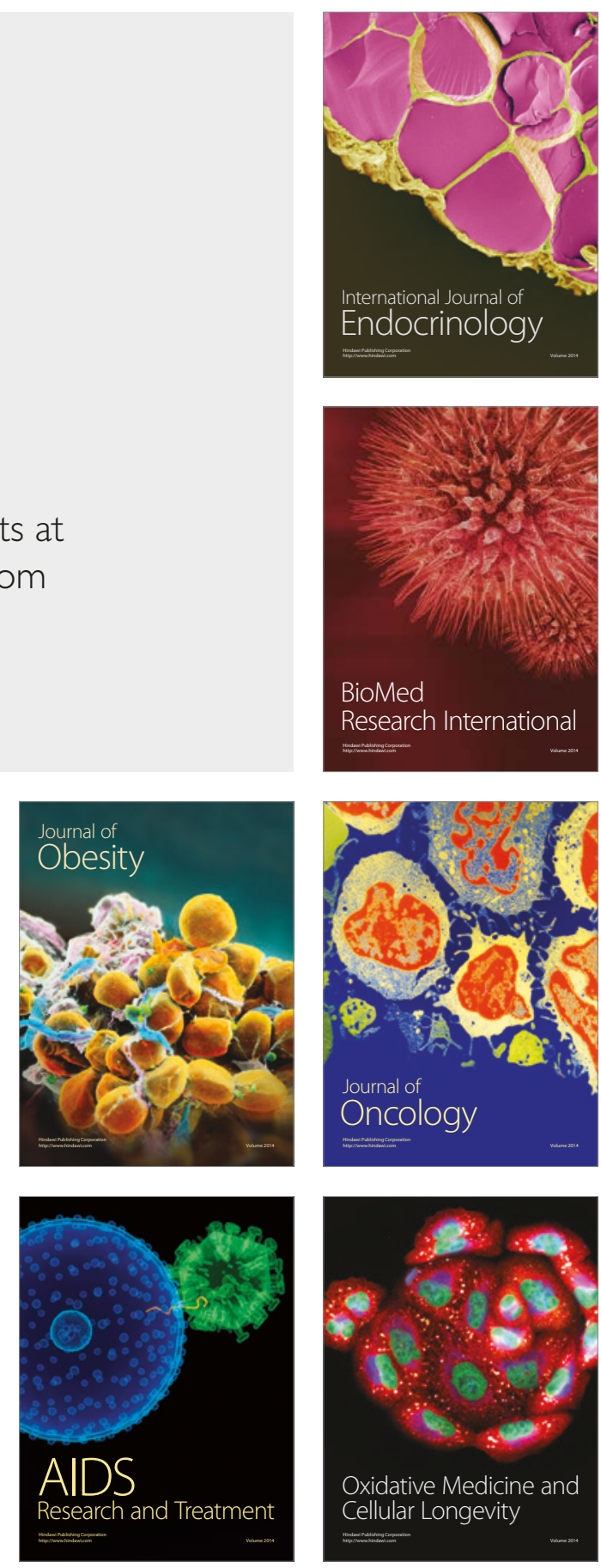